\title{
An interactive web-GIS tool for risk analysis: a case study in the Fella River basin, Italy
}

\author{
Z. C. Aye ${ }^{1}$, M. Jaboyedoff ${ }^{1}$, M. H. Derron ${ }^{1}$, C. J. van Westen $^{2}$, H. Y. Hussin ${ }^{2}$, R. L. Ciurean ${ }^{3}$, S. Frigerio ${ }^{4}$, and \\ A. Pasuto ${ }^{4}$ \\ ${ }^{1}$ Institute of Earth Sciences, University of Lausanne, Lausanne, Switzerland \\ ${ }^{2}$ Faculty of Geo-Information Science and Earth Observation, University of Twente, Enschede, the Netherlands \\ ${ }^{3}$ Department of Geography and Regional Research, University of Vienna, Vienna, Austria \\ ${ }^{4}$ CNR-IRPI, National Research Council of Italy, Research Institute for Geo-Hydrological Protection, Padua, Italy
}

Correspondence to: Z. C. Aye (zarchi.aye@unil.ch)

Received: 28 May 2015 - Published in Nat. Hazards Earth Syst. Sci. Discuss.: 22 June 2015

Revised: 16 October 2015 - Accepted: 15 December 2015 - Published: 18 January 2016

\begin{abstract}
This paper presents a prototype of an interactive web-GIS tool for risk analysis of natural hazards, in particular for floods and landslides, based on open-source geospatial software and technologies. The aim of the presented tool is to assist the experts (risk managers) in analysing the impacts and consequences of a certain hazard event in a considered region, providing an essential input to the decision-making process in the selection of risk management strategies by responsible authorities and decision makers. This tool is based on the Boundless (OpenGeo Suite) framework and its clientside environment for prototype development, and it is one of the main modules of a web-based collaborative decision support platform in risk management. Within this platform, the users can import necessary maps and information to analyse areas at risk. Based on provided information and parameters, loss scenarios (amount of damages and number of fatalities) of a hazard event are generated on the fly and visualized interactively within the web-GIS interface of the platform. The annualized risk is calculated based on the combination of resultant loss scenarios with different return periods of the hazard event. The application of this developed prototype is demonstrated using a regional data set from one of the case study sites, Fella River of northeastern Italy, of the Marie Curie ITN CHANGES project.
\end{abstract}

\section{Introduction}

During recent years, natural hazard and risk assessment has become a major topic of interest among natural and social scientists, engineering professionals, endangered communities and local administrations in many areas of the world (Aleotti and Chowdhury, 1999). At the same time, hazardous processes in mountainous environments such as landslides, debris flows and floods have also increased in terms of frequency, magnitude and impact, as a result of climate change combined with continuously growing settlement areas (Sterlacchini et al., 2014). An increase in occurrences of such hazard events can be expected in the future due to the extreme rainfall events associated with climate change. Landslides happen in different geological and environmental settings in Europe each year (EM-DAT, 2003; EEA, 2010) and are mostly triggered by intense and long rainfall (Krejčí et al., 2002; Zêzere et al., 2005; Guzzetti et al., 2007; Brunetti et al., 2010), though other factors such as rapid snowmelt, earthquakes and human activities also contribute to the occurrences of these events. Natural processes alone present no risk unless they threaten some elements at risk (Alexander, 2004). Therefore, it is important to analyse where these hazard events can occur and with what frequency, as well as the elements exposed to hazard events and their vulnerability (i.e. degree of loss), leading to the identification of areas at risk. Einstein (1988, p. 1076) defined risk as "the multiplication of hazard and potential worth of loss since the same 
hazard can lead to entirely different consequences depending on the use of the affected terrain risk".

Risk assessment and management includes the estimation of the level of risk, followed by an evaluation of whether this level of risk is acceptable. If this is not the case, the adaptation of appropriate measures needs to be taken for risk mitigation (Aleotti and Chowdhury, 1999; Dai et al., 2002; Crosta et al., 2005; Sassa and Wang, 2005; Fell et al., 2008). The acceptable risk is defined as "a risk which everyone impacted is prepared to accept" (ISSMGE TC32, 2004) and varies from country to country (Bell et al., 2005). For management purposes, risk assessment should be able to support the decision-making process in order to contribute to the effectiveness of risk management (Carreño et al., 2007). Therefore, a comprehensive and accurate risk assessment needs to be carried out, realizing its important role in the risk management framework. There are several assessment methods which can be applied depending on the study scale, availability of data and aims of the analysis (Lee and Jones, 2004; Glade et al., 2005; van Westen et al., 2006; Corominas et al., 2014), which can be grouped into qualitative, semiquantitative and quantitative methods. The quantitative assessment of hazard and risk has become an essential practice in risk management (Fell and Hartford, 1997). This approach should quantify the expected losses as the product of the probability for a given intensity, costs of exposed elements at risk or number of exposed people, and their associated vulnerability (Uzielli et al., 2008). However, risk assessments are often complex in nature and many aspects of the risk cannot be fully quantified (Jaboyedoff et al., 2014) due to the lack of data, scale of study or other socio-economic aspects of study area. Therefore, if insufficient data are available for a quantitative assessment, qualitative approaches are adopted, which are often based on spatial multi-criteria evaluation (SMCE) methods (Castellanos Abella and van Westen, 2007; Raaijmakers et al., 2008) and risk matrix approaches (Pine, 2008; FEMA, 2001) for risk prioritization, ranking and evaluation. SMCE is a multi-criteria evaluation method but in a spatial manner, based on the weighting and combination of spatial criteria (maps) to produce a composite map. The risk matrices are also widely adopted due to its simplicity, making it possible to classify and prioritize risk in qualitative classes depending on the levels of impact and probability of a hazard event. In this paper, the scope is limited to quantitative risk estimation (analysis).

Geographical Information Systems (GIS) play a central role in natural hazard risk assessment referenced to a geographical location (Peggion et al., 2008). Nowadays, with the support of advanced internet developments, open-source data, software and technologies, it has become much easier to exchange and analyse spatial information on the web through web-GIS based applications. Web-GIS is the combination of web technologies and GIS for data handling and analysis of spatial data on the web, simplifying the exchange of data and providing structural information to users without needing to install additional stand-alone software (Yang et al., 2005). In recent years, a number of studies have been conducted on the design and development of web-GIS applications for different purposes in the field of natural hazards and risk management (Lan et al., 2009; Frigerio and van Westen, 2010; Pessina and Meroni, 2009; Furdu et al., 2013; OpenQuake, 2015). However, most web platforms have focused mainly on risk visualization and dissemination of information (Müller et al., 2006; Salvati et al., 2009; Giuliani and Peduzzi, 2011; Frigerio et al., 2014) while risk assessment applications still remain as desktop-based applications such as CAPRA-GIS (a modular and free GIS for probabilistic risk analysis of natural hazards) or the InaSAFE (a free and open-source plugin to calculate impact scenarios for natural hazards) of Quantum GIS (QGIS) software. Further research needs to be done on the development of interactive risk analysis and management tools, taking the benefits of advanced web and web-GIS technologies to achieve a centralized and integrated framework. A good example of such developments for earthquake risk assessment was realized based on Geonode (an opensource platform for the creation, sharing and collaborative use of geospatial data) and OpenQuake engine (an opensource software for seismic risk assessment) by the Global Earthquake Model (GEM) foundation. Moreover, with the use of open data, it has become possible to perform rapid damage assessment using OpenStreetMap (Westrope et al., 2014) and its base data can be extracted (Schelhorn et al., 2014) and integrated in web-GIS applications for analysis.

The aim of the paper is to contribute to the practice of the open-source research community through the development of an interactive, open-source web-GIS-based risk analysis tool for natural hazards such as floods and landslides. Section 2 presents the background methodology, workflow and architecture used for the development of the prototype together with the data model design and calculation procedures of the prototype risk tool. In Sect. 3, we demonstrate the components of the prototype using a regional data set from the Fella River basin area in Italy, where flash floods, river floods and debris flows are frequent and cause severe consequences. Finally, a discussion of limitations and potential improvements of the presented risk analysis tool is reported.

\section{Background framework and methods}

An overview diagram of the prototype platform is presented in Fig. 1, where the risk analysis module is one of the main modules. The data management module acts as an essential input to the risk analysis module in order to provide the necessary data (i.e. hazards, elements-at-risk and vulnerability information) for the calculation of loss and risk scenarios. The purpose of the loss component is to quantify the probability of losses either in monetary values or fatalities caused by a hazard event in a specific area for a certain time period. The risk component produces a risk curve which shows the 


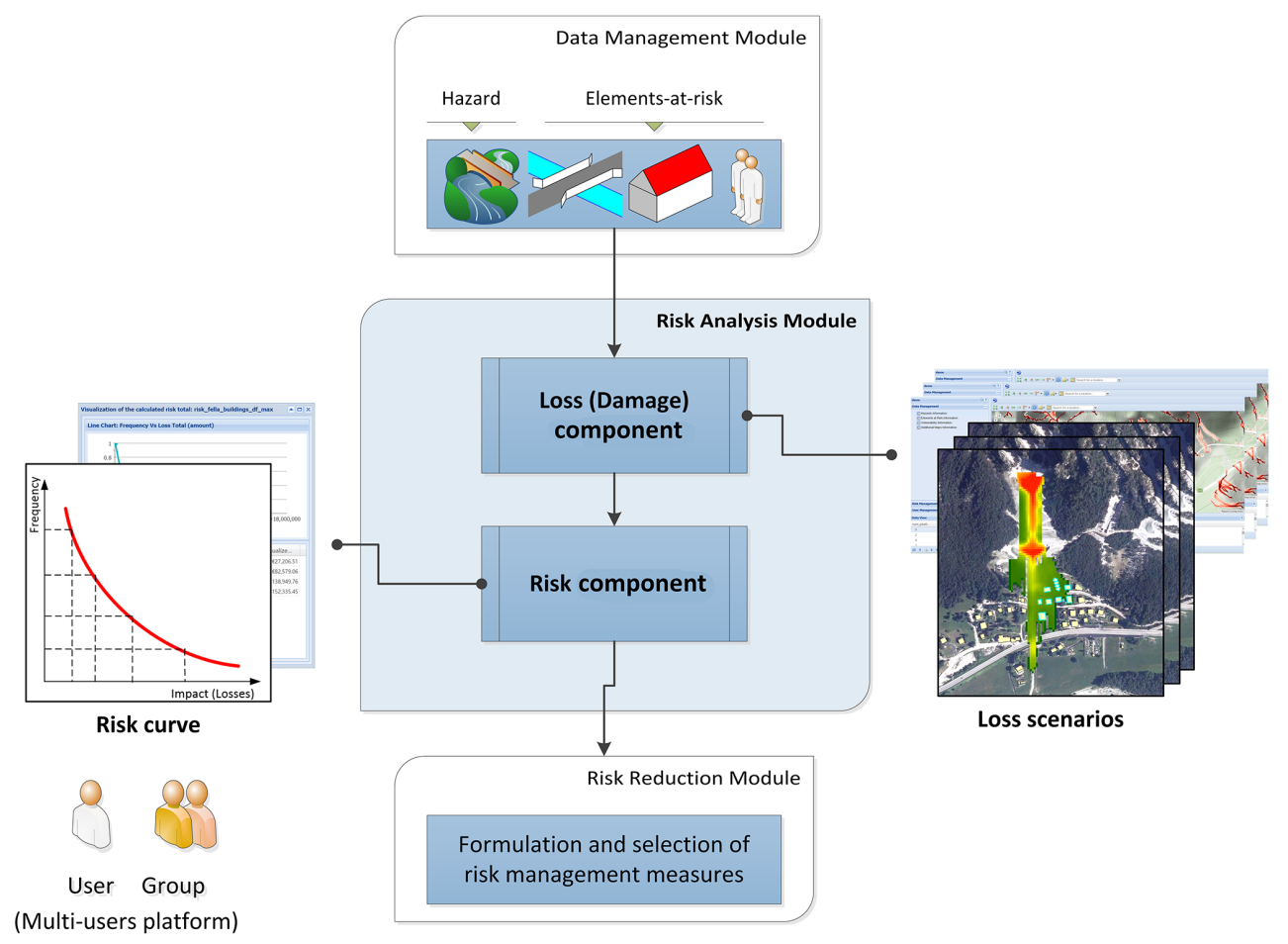

Figure 1. Overview diagram illustrating the main modules of the prototype web-GIS platform. For the user interactions, the risk analysis module is mainly intended for expert users (risk managers) while various stakeholder groups can be involved in the risk reduction module for the decision-making process in the formulation and selection of different risk management measures.

relationship between frequency and its associated losses of hazard events. When the resultant risk level is not acceptable, the results of risk analysis are applied in the decision-making process for formulation and selection of appropriate control measures for the purpose of risk reduction (Aye et al., 2015). In this paper, we mainly focus on the structure of the risk analysis module along with its supporting data management module. The targeted users of this module are mainly experts who are responsible for providing and analysing risk information especially for hydro-meteorological hazards such as floods and landslides.

\subsection{Definitions of loss and total risk}

We define the term "loss scenario" as a scenario with estimated number of fatalities and physical damage to assets in monetary value, which are caused by a specific hazard event with a given intensity for a certain return period. According to Hungr's (1997) definition, intensity represents "a set of spatially distributed parameters describing the destructiveness of a hazard". Intensity can be defined quantitatively using various parameters, e.g. in the case of debris flow, depth of accumulated deposit, impact pressure, kinetic energy per unit area, etc. The return period is the inverse of the average frequency of events with intensities above a given threshold. The physical losses of a certain category of elements at risk for a given frequency of a hazard event can be quantified as (van Westen et al., 2014):

$$
\begin{aligned}
\operatorname{Loss}(L)= & \text { SpatialProbability }(\mathrm{SP}) \\
& \times \operatorname{Vulnerability}(V) \times \operatorname{Amount}(A),
\end{aligned}
$$

where SP is the expected spatial probability values of modelled hazard zones (either a map or a value between 0 and 1) depending on data availability and considered hazard event/type; $V$ is the level of potential damage (or degree of loss) of the affected elements at risk resulting from the hazard event of a given intensity (Fell and Hartford, 1997); A is the quantity (number of people) or economic (monetary) value of the affected elements at risk.

In this paper, only the physical vulnerability of the elements at risk is being considered. The physical vulnerability represents the expected level of damage and can be quantified on a scale of 0 (no damage) to 1 (totally destroyed) in function of the intensity of the phenomenon (Fell et al., 2005). In the prototype, vulnerability data can be represented in the form of data ranges (i.e. a range of minimum and maximum intensity values corresponding to a certain minimum and maximum vulnerability value) or a function with or without class (type) information for a specific category of elements at risk. An example of vulnerability curve is illustrated by the cumulative distribution function (CDF) in Fig. 2, with its 


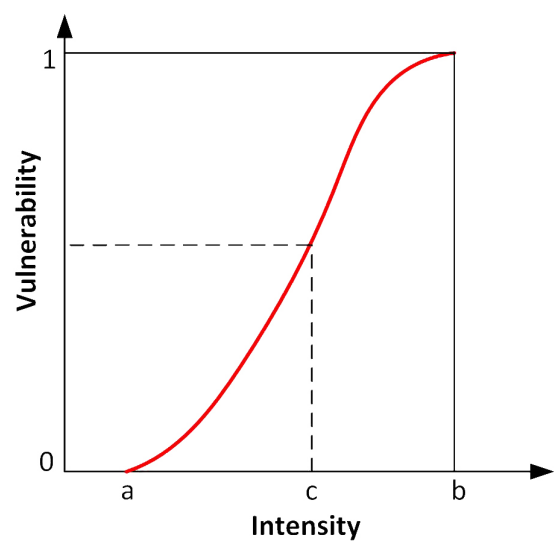

Figure 2. An example illustration of a generic vulnerability curve using a CDF. The input parameters $a, b$ and $c$ are obtained from the user to generate the vulnerability curve with or without class (type) information for a certain category of elements at risk.

defining equation (Kotz and van Drop, 2004; Haimes, 2009):

$\mathrm{CDF}=F(x)=\left\{\begin{array}{l}0, x<a \\ \frac{(x-a)^{2}}{(b-a)(c-a)}, a \leq x \leq c \\ 1-\frac{(b-x)^{2}}{(b-a)(b-c)}, c<x \leq b \\ 1, x>b,\end{array}\right.$

where $x$ is a given intensity value; $a$ is the lowest intensity value; $b$ is the highest intensity value; $c$ is a varying value between $a$ and $b$ values. The CDF is initiated as an example to experiment the possibility of applying a certain vulnerability curve (function) in the loss calculation of this prototype version. The parameter values used to generate this curve are fed directly by the expert user (after having the possibility to perform a detailed analysis outside of the web platform). Therefore, uncertainties could be associated with the expert knowledge of the users.

The resulting loss scenarios (either fatalities or damages) of a specific hazard event with different return periods are then combined to compute the annualized "risk" total $(R)$ per year. It can be represented in the form of a risk curve (van Westen et al., 2010). In this paper, the staircase-shaped curve is applied for the calculation of total risk as illustrated in Fig. 3, showing the contribution of the selected loss scenarios to the annualized total risk $(R)$. Therefore, the resulting annualized risk here represents the area below the staircase rather than the area under the fitted (black) curve of the combination of frequency and loss of all scenarios:

$$
\begin{aligned}
& R=\sum_{j} R_{j} \\
& R_{j}=f_{j} \times L_{j} \\
& f_{j}=f\left(L_{j}\right)=\frac{1}{T_{j}}-\frac{1}{T_{j+1}},
\end{aligned}
$$

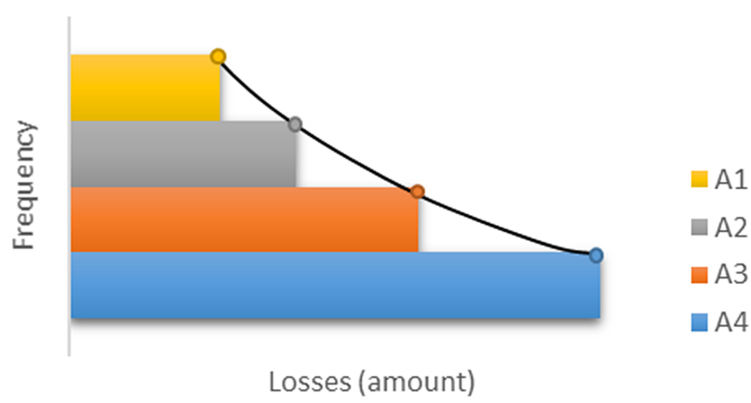

Figure 3. An example of risk curve in the form of staircase. A1A4 represents the area derived from the loss calculation for four return periods. Each $\mathrm{A} 1-\mathrm{A} 4$ contributes to the risk total $(R)$ of the considered hazard event (e.g. debris flows).

where $R_{j}$ is the annual risk of the scenario $j$, the $f_{j}$ is the frequency (inverse of the return period $T$ ) of the scenario $j$, and $L_{j}$ is the loss of the scenario $j$.

A simple conceptualized diagram for the generation of loss and risk scenarios is shown in Fig. 4, where hazard (e.g. debris flows) scenarios with different return periods are overlaid with the elements-at-risk map (e.g. buildings) in order to obtain the intensity associated with each affected object and calculate their vulnerability values, which are finally multiplied with the amount or value of the affected objects. The spatial probability values of the hazard scenarios are also considered in the loss calculation, if available. These resultant loss scenarios are then combined to obtain the total annualized risk. The background layers of debris flows (Hussin et al., 2014a), building maps and vulnerability curves of the example illustrated in Fig. 4 are parts of the research results of two European projects: CHANGES and IncREO.

\subsection{Workflow of the risk analysis module}

The conceptual workflow of the loss component (Fig. 5) is composed of three main parts: hazard, elements-at-risk and vulnerability information. In a first step, the user can select an uploaded hazard map of a certain hazard type. The spatial probability information (either as map or value) can be entered depending on the availability of spatial probability information and selected hazard type. This spatial probability value is given based on the knowledge of the expert user and thus, it can be subjective. If no information is given or available, a spatial probability value of 1 is assumed in the calculation. The user can then move to a second step for the selection of the corresponding elements-at-risk map and enter additional information such as the amount (cost values) and type (class) information depending on the chosen elements at risk, if available. This input information is important in the loss calculation not only to match the existing attributes of a given elements at risk with its corresponding vulnerability information in the next step but also to calculate the estimation of damages. For example, in the case of buildings, 

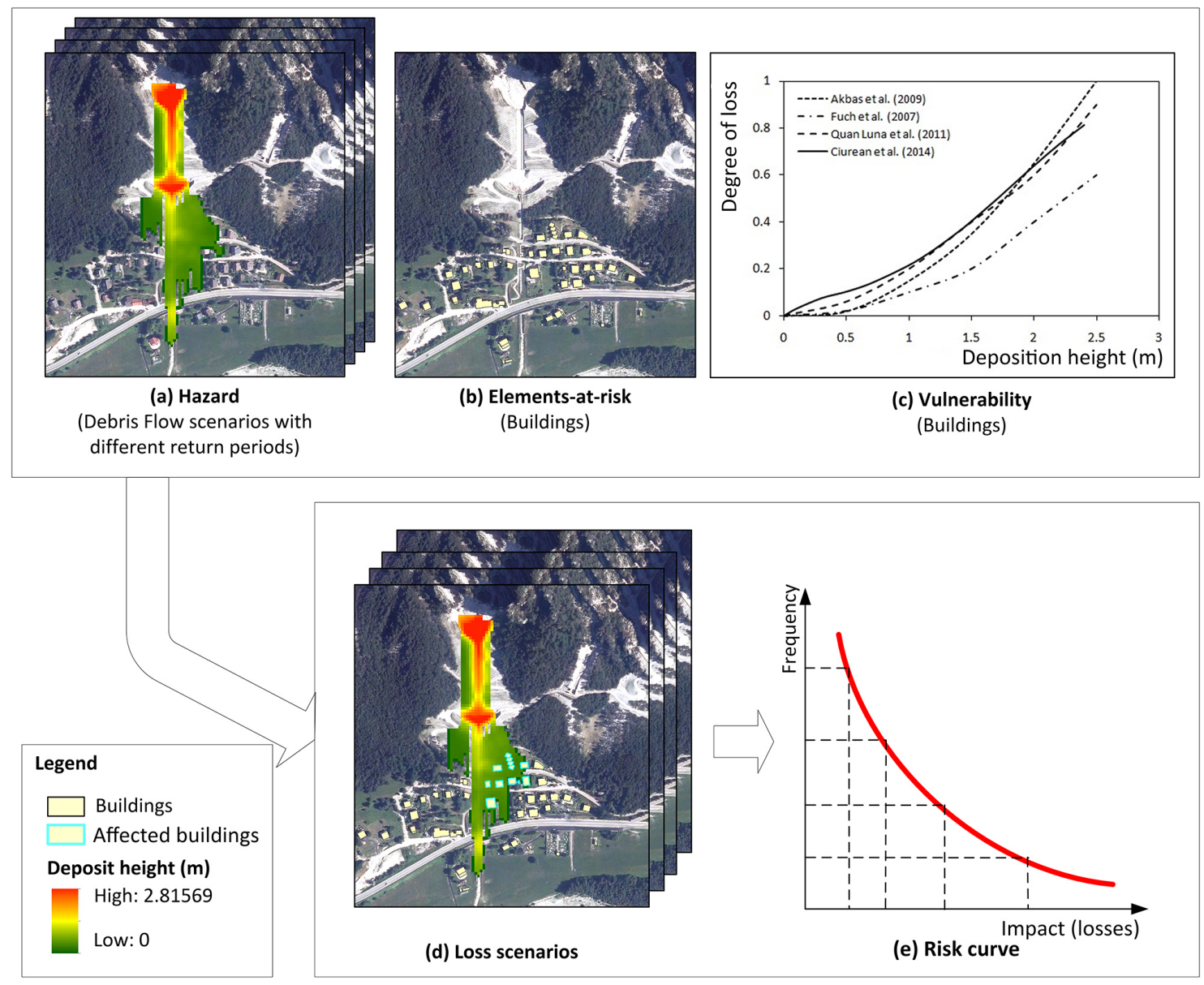

Figure 4. A simple illustration of the generation of loss scenarios and risk curve (adopted from van Westen et al., 2014 with data from Ciurean et al., 2014; Hussin et al., 2014a). (a) Debris flow scenarios with varying colours represent the deposit height (m) of accumulated debris materials for four return periods. (b) Building map consists of the related information such as value and material type of each building. (c) Vulnerability curves of the buildings illustrate a comparison of the considered area's debris flow vulnerability curve with existing ones from the literature. (d) The generated loss scenarios based on (a), (b) and (c). (e) The final risk curve derived from the combination of four loss scenarios with its respective frequency.

the user can indicate the amount (monetary) value and building type (e.g. reinforced concrete, masonry, etc.) information within the selected buildings layer. If no amount information is given or available, only number of affected elements-atrisk calculation is possible (e.g. the number of buildings exposed to the selected hazard scenario). Finally, in a last step, if no vulnerability information is given or available, a vulnerability value of 1 (complete damage) is assumed. If vulnerability data are available, the user can indicate whether it is a "data ranges" or "function", which is either uploaded or created in the data management module by the user. The user then matches the selected vulnerability information with the given class (type) information of the selected elementsat-risk layer. Finally, the loss scenario is calculated on the fly based on these given input data. The resulting calculated loss scenario can be visualized interactively in the web-GIS interface of the platform. This process is repeated for all available hazard scenarios with different return periods and for all elements at risk. The option of setting the spatial probability and vulnerability values to 1 is made available in the case where the associated spatial probability of a hazard event or vulnerability information of elements at risk is not available. Since lack of data is an issue in reality and it is not always possible to obtain a complete data set.

The resulting loss scenarios with different return periods are then combined to produce an annualized risk based on the staircase approach as mentioned above in Eq. (3) and Fig. 3. At least three different loss scenarios of the same hazard event with different return periods are required to calculate the annualized risk and visualize the risk curve within the platform. This process starts with the summation (aggregation) of the losses $\left(L_{j}\right)$ for each loss scenario of certain elements at risk. Then, each loss total is multiplied with the respective frequency value $\left(f_{j}=\frac{1}{T_{j}}-\frac{1}{T_{j+1}}\right)$ to obtain the an- 


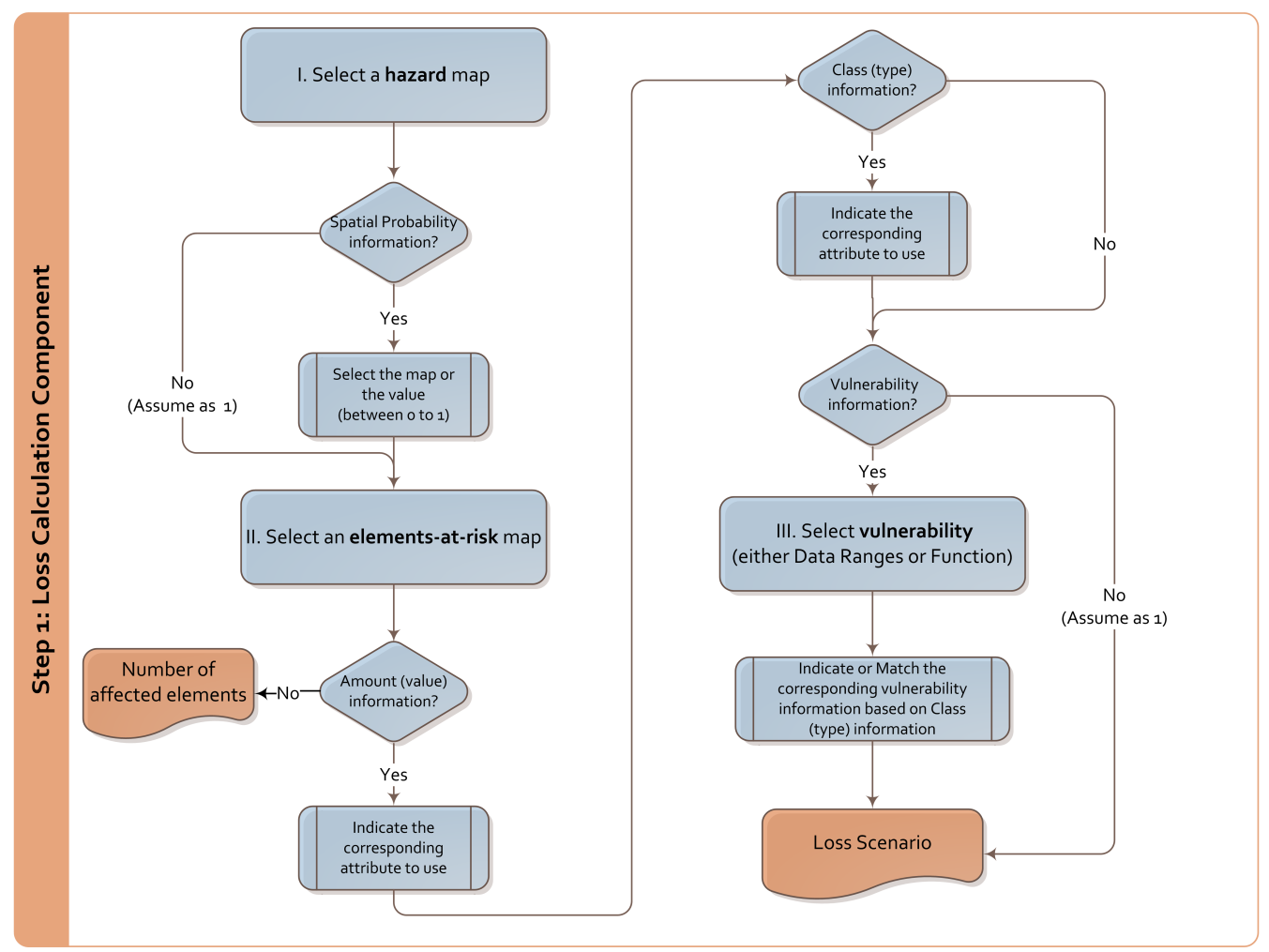

Figure 5. Workflow of the loss calculation component, illustrating the three main types of input information (hazard, elements at risk and vulnerability) with additional parameters for the generation of loss scenarios. For example, if the buildings (as elements at risk) have no amount (monetary) information, only the affected number of buildings can be obtained.

nual risk $\left(R_{j}\right)$ for each step of the staircase curve (Fig. 3), and finally, the summation of all steps $\left(R_{j}\right)$ produces the total annualized risk $(R)$ for the considered hazard event. The stepby-step conceptual workflow of this risk calculation component is shown in Fig. 6, and this process can be repeated for different types of hazards. In the current version of the prototype, we did not consider whether hazards are dependent or not. Moreover, we only considered calculating the area under the staircase-shaped curve, and therefore, there are possibilities to improve the calculation of the entire area under the curve. In addition, the calculation was carried out for the whole study area rather than per administrative units.

\subsection{Background architecture}

The background architecture of the platform is based on the three-tier client-server architecture model, facilitating the maintenance and upgrade of the platform at a later time without needing the users to make changes at the client side (Sugumaran et al., 2004). The processing is done mainly on the server side and only a web browser is needed for the users to access the platform (Aye et al., 2015). The Boundless (formerly OpenGeo) framework was adopted to develop this prototype version of the platform. It offers a complete open-source geospatial architecture with modular compo- nents (Boundless, 2015). Only open-source components and standards are specifically chosen for the development of this web platform. The PostGIS database is integrated for data storage of spatial data. GeoServer and GeoWebCache are used for application servers to access and render the spatial data through web map services. GeoExt, ExtJS and OpenLayers (JavaScript libraries) are applied for the user interface framework of the interactive web map application across web browsers and mobiles. Moreover, it also provides a clientside software development kit (SDK) environment to build JavaScript-based, complete and customizable web mapping applications. This prototype platform is based on GXP template (a JavaScript SDK) for developing high-level GeoExtbased applications with OpenLayers 2. The presented risk analysis and other supporting modules are developed as plugins (dependencies) within the platform. The possibility to develop such customized plugins makes the implemented tools extensible and reusable when and where needed, allowing a faster prototyping with integration of existing map tools and functionality in the web-GIS platform.

\subsubsection{Schema design}

A part of the data model of the prototype platform, focusing mainly on the presented risk analysis module, is illustrated 


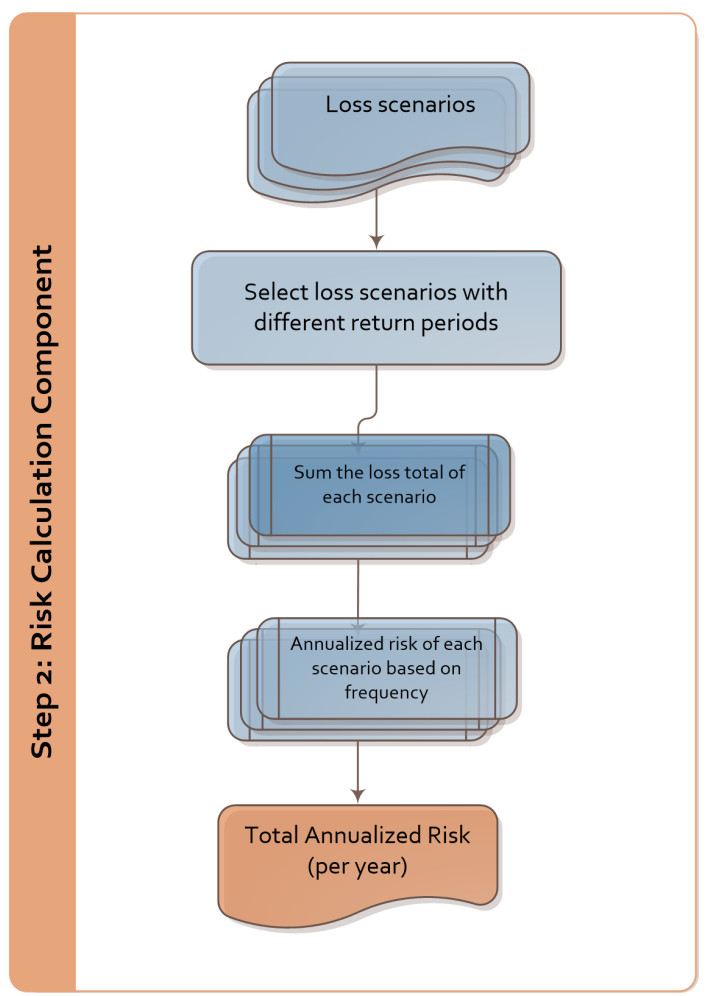

Figure 6. Workflow of the risk calculation component. The loss scenarios with different return periods are combined to obtain the total annualized risk (per year) based on the staircase approach.

in Fig. 7 together with its supporting data management module. The input information related to the hazards, elementsat-risk maps and vulnerability information are recorded in the tables of hazards, elements at risk and vulnerability, respectively. These three tables belong to the data management module. The hazards table records the information related to each hazard map such as type (e.g. floods), return period (e.g. 100 years), name of the hazard map, etc. Similar type of information is also recorded in the elements-at-risk table for all elements-at-risk layers (e.g. replacement value, type and population information). In the vulnerability table, information related to vulnerability data or function curves is recorded. In all cases, the mapping index attribute serves as an important look-up index to link each record in parent tables (e.g. elements at risk) with its corresponding child tables (e.g. Fella buildings) in the database and published layers in the GeoServer. The child tables are created dynamically upon the user uploads of layers (e.g. Fella buildings). Thus, such tables are not included (illustrated) in the fixed schema design of Fig. 7, and their respective column attributes can be varied depending on the uploaded data. Like the other tables, the information related to each loss scenario such as name, description and category of the scenario is recorded in the loss scenario table, and this table is linked to the other three tables (hazards, elements at risk and vulnerability) in order to retrieve the input information which is necessary for the calculation of a specific loss scenario. For the follow-up calculation of the annualized total risk of a certain hazard with different return periods, this loss scenario table is linked with annualized risk table through a loss-risk table since a total risk scenario includes at least three or more loss scenarios with different return periods. The annualized risk table contains the information related to the calculated annualized risk total such as name, description and total amount (per year). The mapping index attribute of this table links to its associated child table which stores the summary information of loss and annualized risk for considered return periods of a certain hazard event.

\subsubsection{Processing steps for calculating losses and risk}

For the loss calculation component, the processing is done mainly within the PostGIS database on the server side and the results of each calculated scenario are published to GeoServer for visualization in the web platform. GeoServer's REST (Representation State Transfer) configuration is used to programmatically configure operations such as creating a new feature type or data store in GeoServer. These published layers can be visualized and edited within the web-GIS interface through Web Map Services (WMS) and Web Feature Services (WFS) of OGC (Open Geospatial Consortium) standards. In the Data Management module, map layers (hazard maps in raster format, and elements-at-risk maps in vector format) can be imported into the database and GeoServer for processing and visualization. The vector layers are stored in a data store linked to the PostGIS database. However, the raster layers are stored separately in a coverage store and in the PostGIS database without having the link between them. For this purpose, the raster2pgsql tool (a raster loader for raster data into a PostGIS raster table) is used through a php (a server-side scripting language) script to store the uploaded raster in the PostGIS database for the loss calculation.

The algorithm for the calculation of a loss scenario within the database has the following steps (buildings as elements at risk, in this case):

1. create a loss table populated with the records derived from the following sub-queries:

a. perform a spatial intersection (ST_Intersects) operation on the hazard intensity raster map and elements-at-risk map based on geometry (spatial) intersection;

b. perform a clip (ST_Clip) operation to crop the intersected raster;

c. perform a polygonized (ST_DumpAsPolygons) operation to obtain raster band pixel values formed by a clipped polygon geometry;

d. perform count, minimum, maximum and average operations on pixel values of the clipped polygons to ob- 


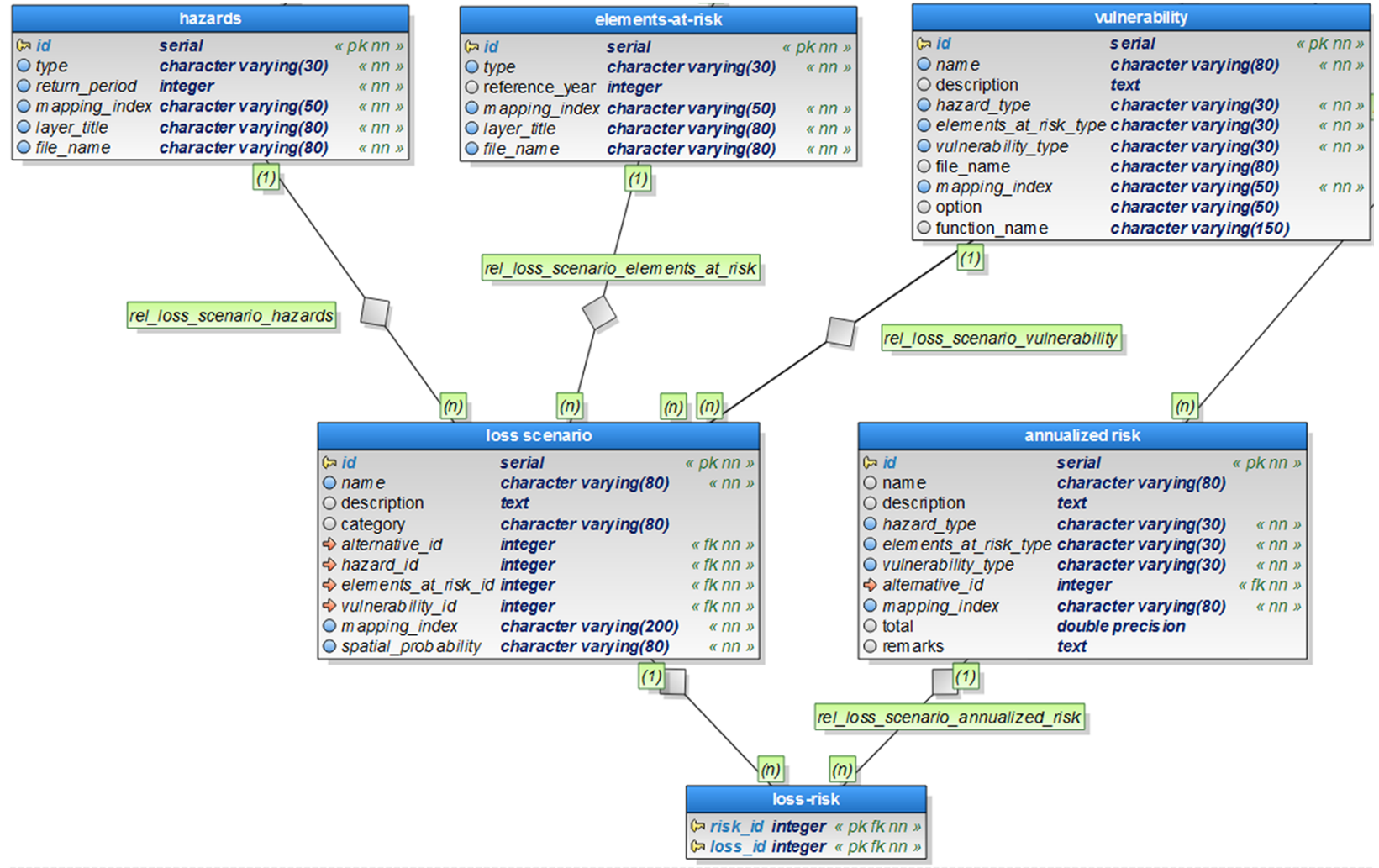

Figure 7. Data Model of Data Management (hazards, elements-at-risk and vulnerability tables) and Risk Analysis (loss scenario, loss-risk and annualized risk tables) modules. Three types of information can be seen in each table: the actual column name (e.g. id), the type of the column (e.g. serial) and the attribute of the column (e.g. «pk nn $\gg$ represents that this is a primary key column and null values are not allowed for this column).

tain the hazard intensity values, grouped and ordered by each affected unique identifier of the objects.

2. add new columns to this created loss table and fill in the respective attribute values (based on the given input information) to calculate loss estimates as follows:

a. extract spatial probability values for each affected object (either from map or given value);

b. extract vulnerability values for each affected object by mapping in the vulnerability look-up table or calculating using the given vulnerability function based on the respective intensity values;

c. extract the corresponding types and monetary values for each affected object by matching in the elements-at-risk map;

d. multiply spatial probability, vulnerability and amount value of each affected object as explained in Eq. (1) and update the loss table accordingly.

3. register the record of this calculated loss table in the loss scenario table of Fig. 7, so that the information can be retrieved later.
As a final step, this calculated loss table is published to the GeoServer for visualization in the platform as mentioned above, using cURL (client URL) and GeoServer's REST configuration. This REST service facilitates the process between the client and GeoServer (e.g. in XML format, Extensible Markup Language) through HTTP (Hyper Text Transfer Protocol) calls to create, retrieve or update information of something in GeoServer - for example, to add a new style or change the name of a certain published layer in GeoServer (only if the logged-in user has the authorization to do so).

After calculating each loss scenario for different return periods of a considered hazard, the algorithm for the total annualized risk is performed as follows:

1. create a total risk table that stores the information about a collection of considered loss scenarios (i.e. return period, frequency, number of affected elements-at-risk, loss and annual risk values):

a. populate the table with records of return period, frequency and its corresponding losses;

b. update the table's risk attribute value to compute the annual risk (the calculation as explained in Sect. 2.2 and Fig. 6). 


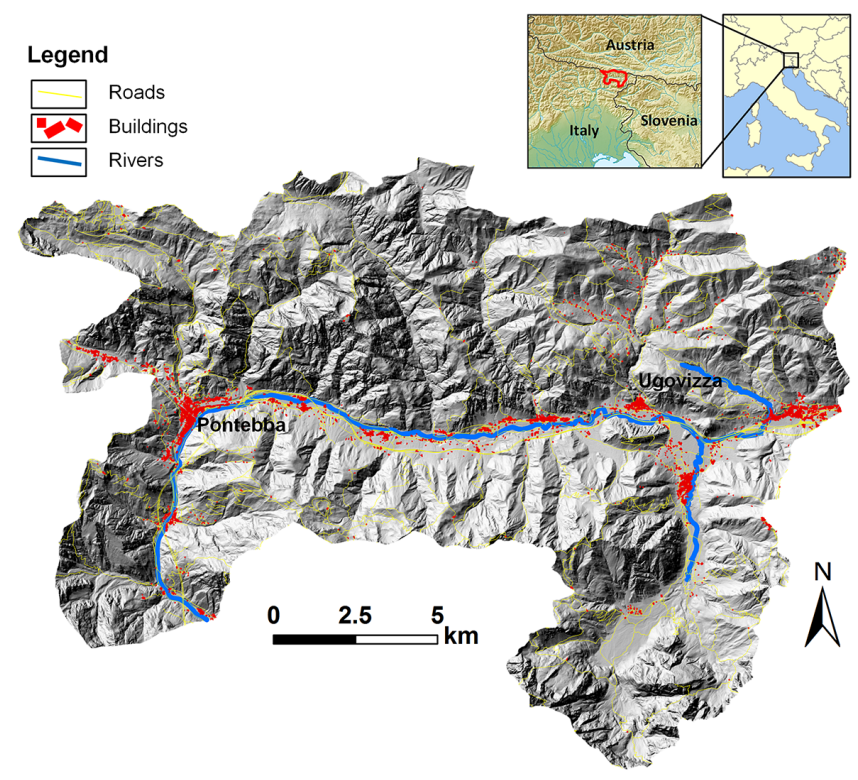

Figure 8. The Fella River study area, Friuli-Venezia Giulia region, northeastern Italy (Data from Chen et al., 2014; Ciurean et al., 2014; Hussin et al., 2014b).

2. register the summed annual risk total record in the annualized risk table of Fig. 7 along with additional information.

3. register the relationship record in the loss-risk table of Fig. 7 to link between loss and annual risk scenarios.

The snippets for loss and risk calculation are accessible at the following link for interested readers: https://bitbucket. org/snippets/zaye/.

\section{Demonstration of the prototype}

\subsection{Case study of Fella River basin, Italy}

The Fella River is a left tributary of the Tagliamento River, the dominant river system in the Friuli-Venezia Giulia region, northeastern Italy (Cattaneo et al., 2006). The study area is $247 \mathrm{~km}^{2}$ in size (Fig. 8) and the catchment has an average altitude and mean precipitation of $1140 \mathrm{~m}$ a.s.l. and $1920 \mathrm{~mm}$, respectively (Sangati, 2009). The drainage has a torrential regime due to the concentrated rainfall in intense and erosive showers, the steep topography and the lithology consisting a large part of limestone and dolomite. In addition, the area is seismically active and characterized by a high distribution of landslides (Borga et al., 2007). Extreme precipitation events leading to hydro-meteorological hazards such as flash floods, landslides and debris flows are frequent in the area, resulting in catastrophic consequences and damages to infrastructure worth hundreds of millions of euros and human casualties (Scolobig et al., 2008).

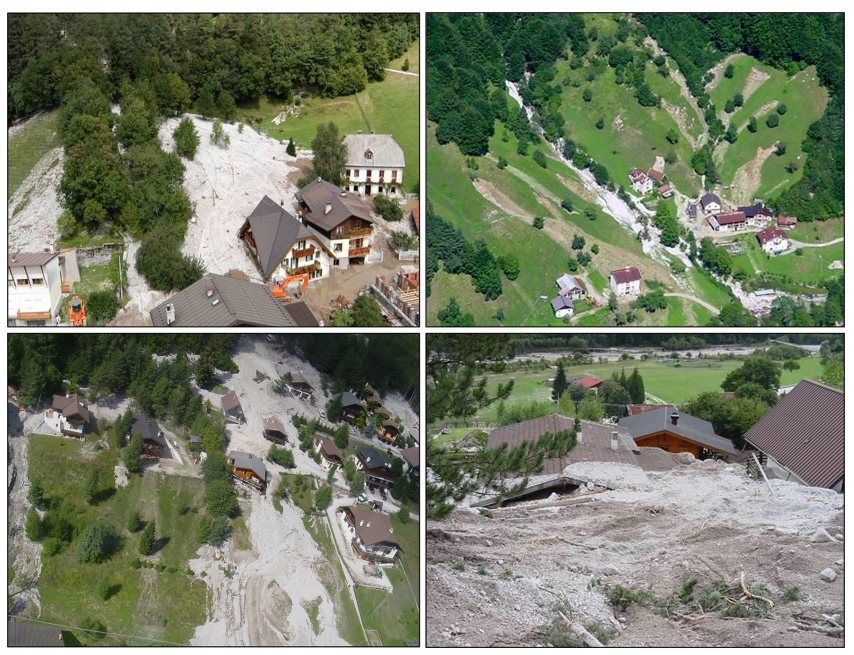

Figure 9. Debris flow events in Fella River basin in August 2003 ( ${ }^{\circledR}$ Civil Protection of Friuli-Venezia Giulia region, Italy).

In August 2003, a major alluvial event occurred, triggering landslides and debris flows mobilizing about 1 million cubic metres of debris material and causing a major flood on the whole Fella River basin (Fig. 9). Moreover, shallow and deep-seated landslides and flash flooding also occurred in this area (IncREO, 2014). Despite being scarcely populated, the valley represents an important transportation and communication corridor in the region, with a high interest of local authorities and population in tourism activities. Therefore, an expansion of touristic and recreational areas could result in more elements at risk affected and thus an increase in potential risks to hydrometeorological hazards.

\subsection{Fella River data set}

For debris flow hazards, four types of events have been modelled by Hussin et al. (2014b): frequent, minor, moderate and major with related estimated return periods of 1-10 years, $10-25$ years, $25-100$ years and $100-500$ years, respectively. This model is an empirical regional-scale model with some limitations that gives only the run-out extent. By using the expert-based approach and comparing with past events, impact pressure intensities are given to these run-outs. The modelled impact pressure (in $\mathrm{KPa}$ ) is considered as the intensity parameter for the debris flows. Figure 10 illustrates the major debris flow event of a part of the Fella study area for the return periods of 100-500 years. The modelled debris flows have not all occurred. However, they are all possible debris flows that could occur in the study area if they were to be triggered, and based on a susceptibility analysis of the most likely areas to be debris flow sources in the future. Their intensities (including run-out distance and extent) correspond to similar events with a return period scenario that have occurred in the past. The set of modelled debris flows 


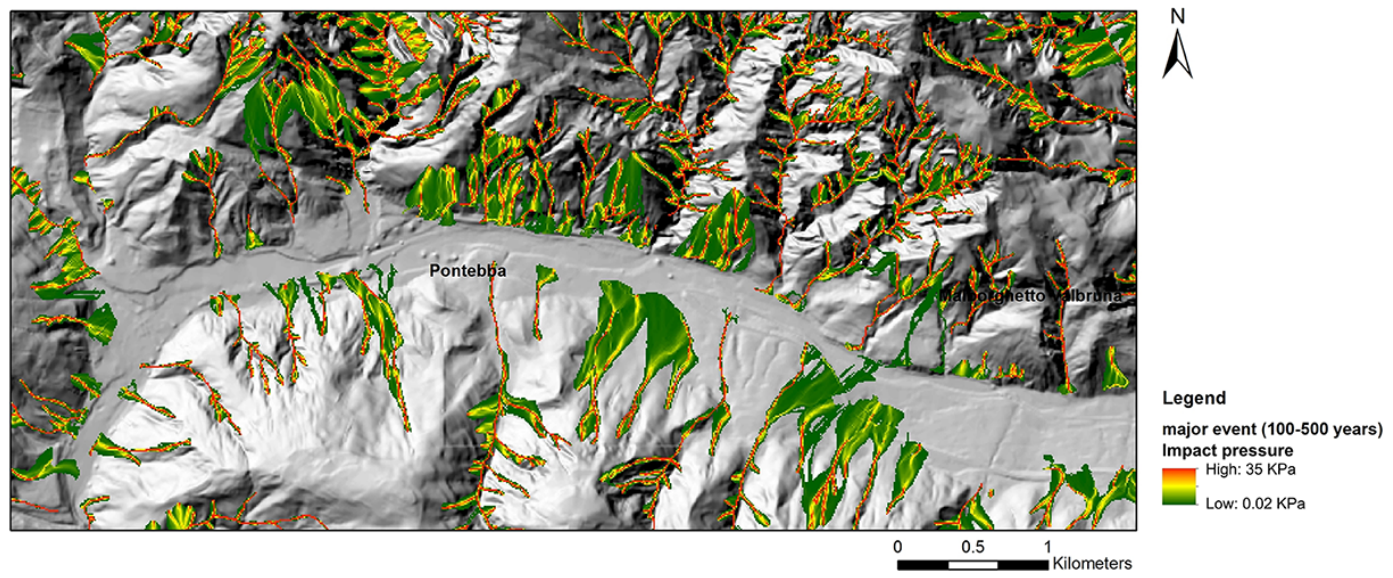

Figure 10. Debris flow (maximum intensity) of major event with return periods of 100-500 years (Hussin et al., 2014b).
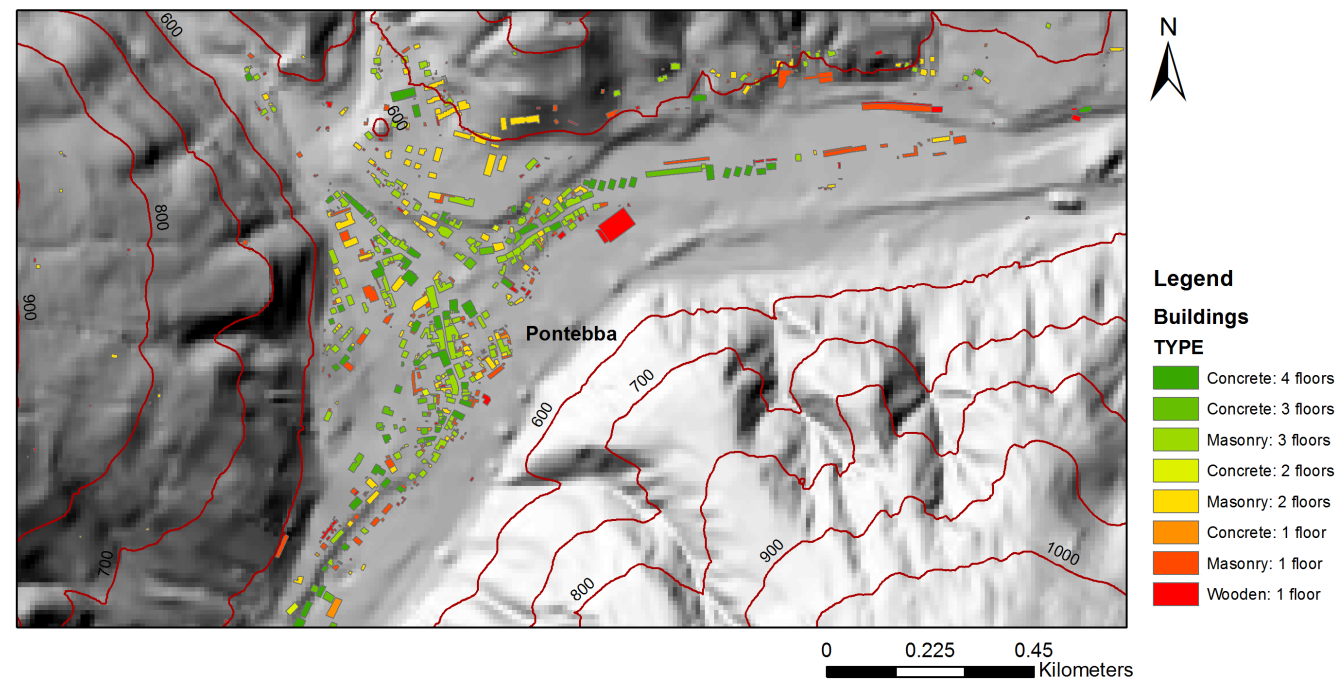

Figure 11. Classified building information in Pontebba commune, Fella River basin (Ciurean et al., 2014).

were simulated according to a calibration with debris flow events occurring in each return period scenario.

The elements-at-risk database contains information about building characteristics such as location, occupancy type, material of construction, number of floors, building's value (minimum and maximum) and number of people occupying the building (during tourist and non-tourist seasons) (Ciurean et al., 2014). The building database was developed using an initial digital data set which was subsequently updated and validated through GIS-desktop and field mapping, which gave information about the building geometry, type, use, etc. Building value was calculated based on existing cadastral information, whereas population at individual building level was estimated using a dasymetric mapping technique. An illustration of the building classification based on construction material and numbers of floors in Pontebba commune is given in Fig. 11.

\subsection{Uploading of Fella data in the data management module}

As a first step to calculate loss and risk scenarios, the input data needs to be imported into the platform through the data management module, i.e. hazard intensity maps, elements-atrisk maps and associated vulnerability information. If available, the spatial probability map associated with a certain hazard event can also be uploaded into the system to be included in the calculation. For example, spatial probability of debris flow can be calculated by overlaying the modelled debris flow areas with actual inventories corresponding to each return period. All debris flow areas that are part of the historical inventory are given a spatial probability of 1 . The spatial probability of the simulated debris flows that do not overlap with past events are calculated by dividing the total area of the historical events of a given return period scenario by the total area of the modelled debris flows of that scenario 


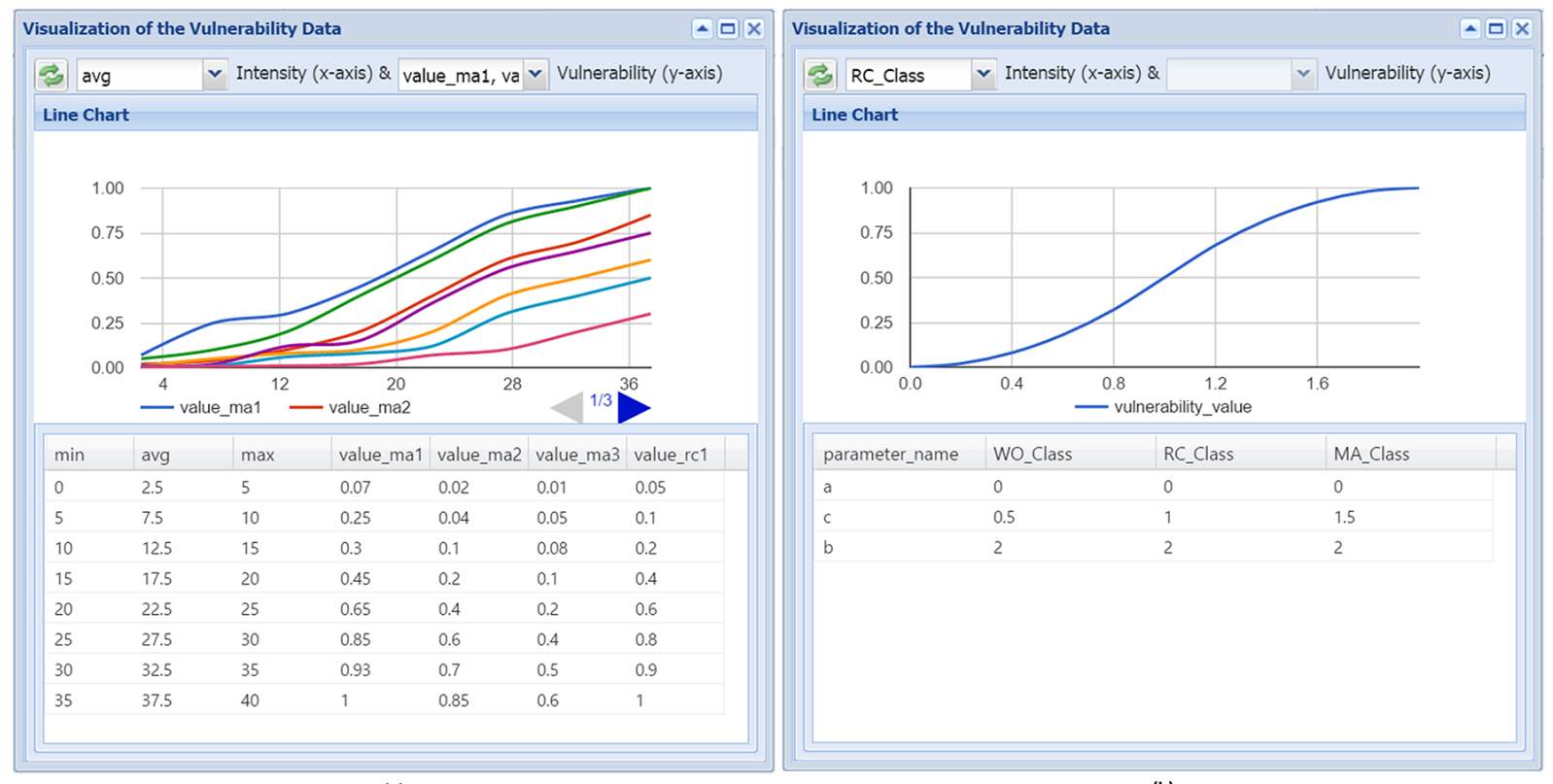

(a)

(b)

Figure 12. (a) Visualization of the vulnerability curves generated using data ranges. The curves are drawn based on the average intensity values for different building material types such as masonry 1 floor, reinforced concrete 1 floor, etc. (b) Visualization of the vulnerability curve generated using the CDF. The curve is drawn based on Eq. (2) for the building material type (e.g. reinforced concrete). The input parameter values $a, b$ and $c$ are given by the user.

(Hussin et al., 2014b). The users can upload data in .tiff format for raster images or zip format for vector shapefiles. The additional properties of the imported layers are also recorded in the system, such as type and return period (in case of hazards), and the indication of whether the imported map reflects the current situation or a possible future situation after implementing certain measures (for risk reduction module of the platform). Upon successful upload of maps to the system, the users can visualize, edit, query and style the layers in the web-GIS interface of the platform.

For the vulnerability component, the user can enter data in the form of numerical values (data ranges) or functions to calculate vulnerability curves. The "data ranges" is a discrete range of minimum and maximum degree of loss values associated with the corresponding minimum and maximum intensity of a certain hazard event, and it can be uploaded by the users in .csv, excel and .txt formats. The "function" option is used to create a continuous CDF together with its specific parameter values, as defined by the users and explained in Eq. (2). The CDF must fulfil two mathematical requirements: (a) the depending variable, i.e. degree of loss, should be confined by the [0-1] interval; and (b) it should increase steady and monotonic with the interval of the explaining variable, i.e. intensity (Papathoma-Köhle et al., 2012). Such examples of probability functions are the Weibull, Fréchet, log-logistic, triangular, beta, etc. The visualization of vulnerability curves obtained by using both options is demonstrated in Fig. 12a and $b$, where the average curves obtained from a set of data ranges and a generic CDF are illustrated respectively. The import interfaces of the hazard and vulnerability components are included in the Supplement for demonstration.

\subsection{Risk analysis module}

Each loss scenario is then calculated in the Loss Component of the Risk Analysis module using the available maps and information in the system. As explained in Sect. 2.2, the loss component is composed of three main parts: hazards, elements-at-risk and vulnerability information for calculation of a new loss scenario (see the Supplement for the loss interface). The users can first select a "hazard" map amongst the existing ones depending on the hazard type (e.g. debris flows or floods) and its corresponding spatial probability data can be entered either in the form of map or input value in the range of 0 to 1 . For the "elements-at-risk" part, the same concept applies, allowing the users to select an existing map (e.g. buildings) as well as to enter additional parameters such as amount (e.g. building value) or different class information (e.g. material type) of the selected elements-atrisk layer. Only the number of affected elements at risk can be calculated if no monetary information of the elements at risk is given. In the "vulnerability" part, the user can indicate whether vulnerability information is available or not. In the case of no information, we assume that the affected elements will be totally destroyed (i.e. vulnerability value equals 1 ) regardless of hazard intensity. If not, the user can select the available vulnerability information based on its data type (ei- 


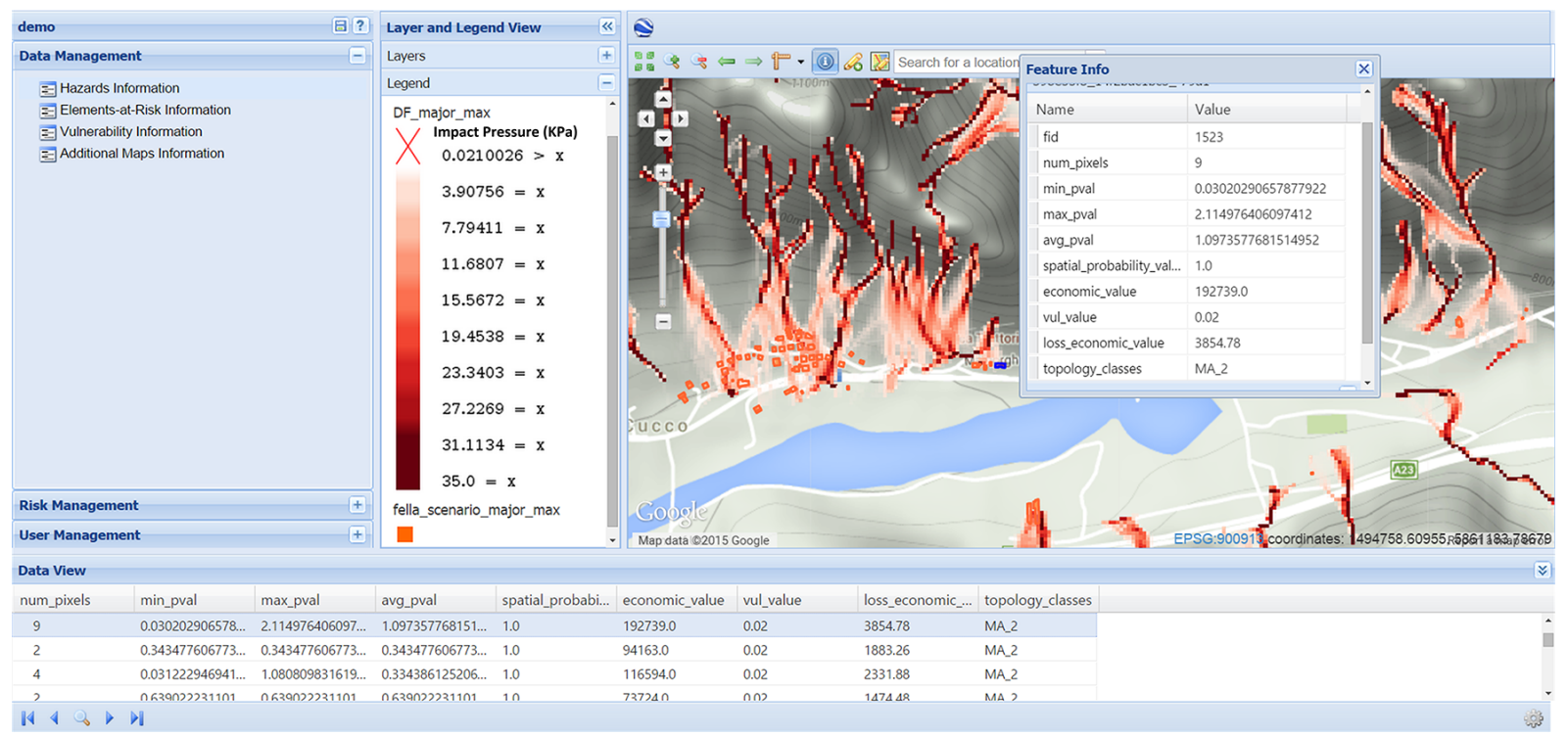

Figure 13. Visualization of the calculated loss scenario, illustrating the affected buildings with economic losses for the debris flow major event (maximum intensity in $\mathrm{KPa}$ ).

ther data ranges or function). Then, the user can match the vulnerability data with classes of objects (e.g. material types) accordingly to retrieve the corresponding vulnerability value of a certain intensity level on each affected object.

Based on these three types of input information, a new loss scenario is calculated according to the loss algorithm described in Sect. 2.3.2. Thereafter, the user can visualize each calculated loss scenario (Fig. 13) where the economic loss (damage) of each affected building by the debris flow hazard can be seen in the pop-up of the map interface. The additional information used to calculate the loss is also presented such as minimum, maximum and average intensity values, vulnerability value based on the building's material type, spatial probability and monetary value of the building.

This loss calculation process is repeated for all return periods of a given hazard (in this case, debris flows). After that, these loss scenarios with different return periods of the debris flow event are combined to calculate the annualized risk, as mentioned in Sect. 2.3.2. At least three or more loss scenarios with different return periods are required for the Risk Component of this module (see the Supplement for the risk interface). The visualization of calculated minimum (Fig. 14a) and maximum (Fig. 14b) risk curves for debris flow events in the Fella River study area is demonstrated, along with affected number of buildings and their corresponding losses for each return period of the calculated scenarios.

According to the calculation results, Fig. 14 shows that high return period events (i.e. low-frequency events) caused higher losses compared to the low return period events (i.e. high-frequency events). For the maximum intensity scenarios of debris flow, the economic losses of the major event reached EUR 15 million (703 houses were affected) while the most frequent event was only EUR 30 thousand (seven houses were affected). The variation in risk estimation can be indicated with minimum and maximum values of total economic losses - for example, in the case of major debris flow event, the difference ranges from EUR 3.7 to 15 million. The total annualized risk for debris flow is estimated approximately from EUR 0.026 to 0.4 million (for minimum and maximum scenarios, respectively).

For the same study area, risk assessment has been carried out by Chen et al. (2014) in which a multi-hazard quantitative risk assessment model was developed using a historical hazard inventory and GIS technology for risk curves generation and annualized risk calculation. The results of the webGIS risk analysis tool were compared with the ones produced by Chen et al. (2014). For number of affected buildings, the difference varied from 0 to 100 with an increase in return periods of the events. Fewer buildings were affected as a result of calculations in the web-GIS tool with a difference of 4-10 buildings for minor events, $38-40$ buildings for moderate events and 90-100 buildings for major events, while there was no difference for frequent events. Within the webGIS tool, $5 \times 5 \mathrm{~m}$ cell sizes of the debris flow raster maps (with $100 \times 100 \mathrm{~m}$ tile sizes) were used for calculation within the PostGIS database. This cell grid size $(5 \times 5 \mathrm{~m})$ was chosen since it gives better approximate results when compared to Chen et al. (2014), according to the test results obtained by using different cell size raster maps. If a building polygon was overlapped to multiple pixels of the debris flow raster map, the maximum intensity value of the overlapping pixels was used to retrieve the vulnerability value for loss calculation. A spatial probability value of 1 was applied in the loss calculation for the underestimated (modelled) de- 


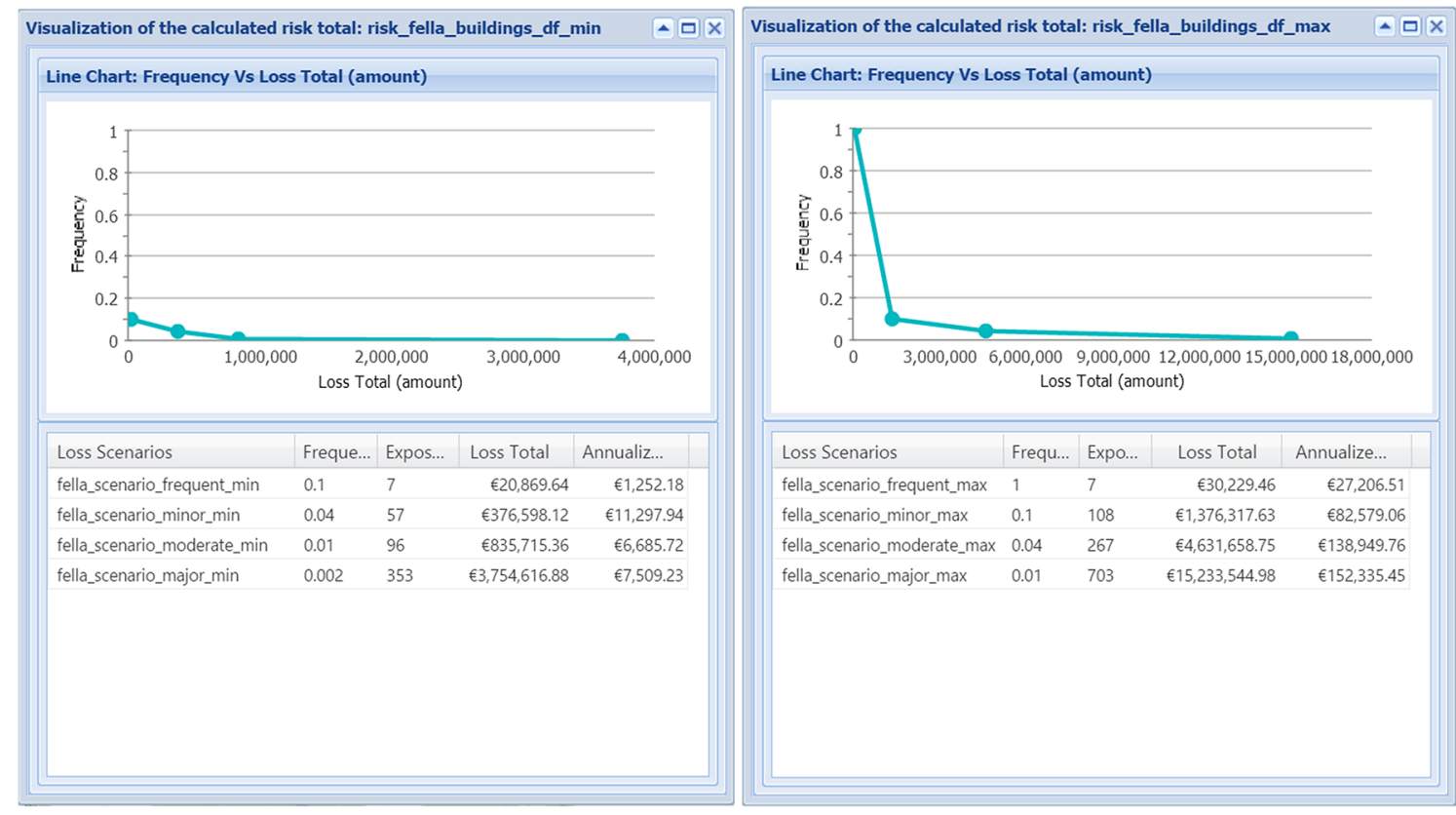

(a)

(b)

Figure 14. (a) Visualization of the debris flow risk curve (minimum). (b) Visualization of the debris flow risk curve (maximum).

bris flow maps. This value was chosen based on the expert knowledge and assumption that this area witnessed debris flows in the past completely (i.e. historic debris flow events). Debris flows that have occurred in channels in the past are more likely to also occur in the future. Due to discrepancies in raster cell size and spatial probability values, the calculated loss values showed a difference of about EUR 7 million for major events while comparable results were achieved for moderate, minor and frequent events.

\section{Discussion and conclusion}

This paper has presented the design and development of a web-based risk analysis tool which aims to assist in analysing the impact of flood and landslide events on society and people, with the demonstration of the prototype using a data set from Fella River basin located in northeastern Italy, where frequent floods and landslides occur with severe consequences for the infrastructure and mountainous community in the region. The presented tool is developed as a module of a prototype decision support platform so that the risk managers can not only analyse areas at risk but also formulate and compare different risk reduction measures with involvement of other stakeholders from different institutions and organizations (see Aye et al., 2016 for the collaborative framework of the platform). This risk analysis tool has been developed based on the feedback of local stakeholders during a workshop organized in Malborghetto Valbruna municipality of Fella River basin in September 2014. The stakeholders indicated their strong interest in the potential development of a spatial-query-based risk analysis tool along with a cost-benefit analysis tool for comparison of different risk reduction measures in the area. As a first step, this prototype scenario-based risk analysis module was developed. As stakeholders suggested, the possibility of integrating a spatial-query-based tool could further facilitate the risk analysis process in a much more interactive, query-based environment (for example, drawing a polygon query for risk calculation in the web-GIS interface of the platform for a certain area of interest).

Considering that this prototype is in the development phase but represents an essential step towards a more complex risk analysis platform, further improvements of the developed risk analysis tool can be identified. For example, the vulnerability component could be advanced with the integration of additional vulnerability curves for specific hazards and elements-at-risk types. For the loss component, at its current state, loss scenarios are calculated one by one based on input parameters, and therefore, the manual input iteration time of the same process could be reduced with the integration of a batch processing mode. This can be done for all loss combinations of hazards with different return periods and elements-at-risk scenarios. The uncertainty of the chosen input parameters in the process should also be communicated to the user. Besides, it is also planned to integrate qualitative hazard intensity layers in vector format in the loss calculation. For the risk component, more accurate ways of calculating the total annualized risk under the area of risk curves (i.e. over the combination of loss scenarios with frequency) could be explored, and visualization of risk curves could be im- 
proved by considering different hazards for multi-hazard risk assessment. In this study, all input data required were available and imported into the platform. However, availability of hazard intensity (raster) maps and elements-at-risk information can be rather limited for such kind of full quantitative risk analysis, especially in developing countries. Therefore, other approaches dealing with lack of data should also be further integrated within the platform - for example, a qualitative impact-probability matrix to assess and compare different situations for affected elements at risk at object level based on expert and local knowledge of the territory. Data scarcity can also be overcome through simulation based on value distribution for missing variables and/or adding variables to the existing data, and this would lead to obtaining exceedance curves by running several and random simulations.

This prototype tool was developed based on Boundless architecture and its client-side environment due to its flexible and extensible open-source components, making it possible to implement a faster prototyping of the tool. Regarding technical improvements of the tool, the loss scenarios were generated in the spatial database hosted on the server side of the web application. Therefore, raster and vector layers had to be imported into the database to perform spatial operations and published to GeoServer for visualization purposes in the platform. If the calculation processing of loss scenarios could be directly carried out using Web Processing Services (WPS), the importation and publishing procedures to the database and GeoServer could be minimized. Furthermore, moving forward to implementing WPS for loss and risk calculation could assist in particular for recalculation of loss and risk scenarios dynamically for different risk reduction measures, at least for preliminary risk calculations without needing the users to re-upload the new updated hazard (raster) maps. In that case, it would greatly simplify and reduce the complexity of the steps used to recalculate risk for reduction measures, which is required for the risk reduction module of the platform. Additionally, risk calculation could benefit from the use of remote data sources from other available web map servers and services provided by responsible organizations of the study area.

To conclude, regardless of some limitations of the presented approach, the prototype tool was successfully realized as an initial outcome of a prototype decision support platform, and its possible application was demonstrated to the stakeholders and tested using a real data set from the Fella River basin study area. This prototype plays an important role in obtaining feedback and suggestions from potential stakeholders and users of the application, leading to a full-scale development of the system based on a user-centred designed approach. Additionally, rather than being a standalone risk analysis tool, this tool has been integrated within a decision support platform. The great benefit lies in achieving an integrated risk management framework which supports the end users and stakeholders in better understand- ing the entire process of risk management starting from risk identification to the selection of risk management strategies, while providing a centralized and collaborative multi-users platform. Furthermore, this simple risk analysis tool is developed based on a generalized framework with use of opensource software and architecture, and hence it offers a high degree of replicability and mobility in other study areas. Unlike desktop-based applications, the end users need not install additional plug-ins or GIS software to analyse risk, and the resultant risk information can be visualized and shared amongst the users for efficient communication and dissemination over the web, benefiting from web-GIS and web technologies. Several functionalities for improvements are planned for future development such as qualitative impactprobability matrix for risk analysis at object levels, integration of additional vulnerability curves and simulation approaches as well as for working with (semi) qualitative hazard intensity maps. As a final point, we plan to make the developed tool open-source and freely accessible at the end of the development in order to contribute towards the opensource research community in the field of natural hazard risk management.

\section{The Supplement related to this article is available online at doi:10.5194/nhess-16-85-2016-supplement.}

Acknowledgements. The authors would like to express their heartfelt thanks to the local stakeholders (the Civil Protection and Geological Survey of Friuli-Venezia Giulia region). We also like to thank our research colleagues from the CHANGES (Changing Hydro-meteorological Risks as Analyzed by a New Generation of European Scientists, Grant Agreement No. 263953) and IncREO (Increasing Resilience through Earth Observation-IncREO, Grant Agreement No. 312461) projects for data sharing of their research results and cooperation in this study area. We also thank editor and two anonymous reviewers for their helpful comments and suggestions for the improvement of the manuscript. This presented work is carried out under the CHANGES project, a Marie Curie Initial Training Network funded by the European Commission's 7th Framework Program (2011-2014).

Edited by: B. D. Malamud

Reviewed by: two anonymous referees

\section{References}

Akbas, S. O., Blahut, J., and Sterlacchini, S.: Critical assessment of existing physical vulnerability estimation approaches for debris flows, in: International Conference on Landslide processes: from geomorphological mapping to dynamic modelling, edited by: Malet, J. P., Remaitre, A., and Bogaard, T., Strasbourg, 6-7 February 2009, 229-233, 2009. 
Aleotti, P. and Chowdhury, R.: Landslide hazard assessment: summary review and new perspectives, Bull. Eng. Geol. Environ., 58, 21-44, 1999.

Alexander, D.: Natural hazards on an unquiet earth, in: Unifying Geography, Shared Future, Common Heritage, edited by: Matthews, J. and Herbert, D., Routledge, London, 266-282, 2004.

Aye, Z. C., Jaboyedoff, M., Derron, M.-H., and van Westen, C. J.: Prototype of a web-based participative decision support platform in natural hazards and risk management, ISPRS Int. J. Geo-Inf., 4, 1201-1224, 2015.

Aye, Z. C., Sprague, T., Cortes, V. J., Prenger-Berninghoff, K., Jaboyedoff, M., and Derron, M.-H.: A collaborative (web-GIS) framework based on empirical data collected from three case studies in Europe for risk management of hydro-meteorological hazards, International Journal of Disaster Risk Reduction, 15, 10-23, 2016.

Bell, R., Glade, T., and Danscheid, M.: Risks in defining acceptable risk levels, in: Landslide Risk Management, supplementary, edited by: Hungr, O., Couture, R., Eberhardt, E., and Fell, R., Taylor \& Francis, London, 400, 38-44, 2005.

Borga, M., Boscolo, P., Zanon, F., and Sangati, M.: Hydrometeorological analysis of the 29 August 2003 flash flood in the Eastern Italian Alps, J. Hydrometeorol., 8, 1049-1067, 2007.

Boundless: available at: http://boundlessgeo.com/, last access: 31 May 2015.

Brunetti, M. T., Peruccacci, S., Rossi, M., Luciani, S., Valigi, D., and Guzzetti, F.: Rainfall thresholds for the possible occurrence of landslides in Italy, Nat. Hazards Earth Syst. Sci., 10, 447-458, doi:10.5194/nhess-10-447-2010, 2010.

Carreño, M. L., Cardona, O. D., and Barbat, A. H.: A disaster risk management performance index, Nat Hazards., 41, 1-20, 2007.

Castellanos Abella, E. A. and van Westen, C. J.: Generation of a landslide risk index map for Cuba using spatial multi-criteria evaluation, Landslides, 4, 311-325, 2007.

Cattaneo, A., Salmoiraghi, G., and Gazzera, S.: The rivers of Italy, in: River and stream ecosystems of the world, University of California Press, Berkeley, 832 pp., 2006.

Chen, L., Hussin, H. Y., Ciurean, R. L., Turkington, T., van Westen, C. J., Chavarro, D., and Shrestha, D.: Multi-hazard risk assessment in Fella Basin (Italy) using historical hazard inventory and GIS, in: Proceedings of the International Conference on Analysis and Management of Changing Risks for Natural Hazards, Padua, Italy, 18-19 November 2014.

Ciurean R. L, Chen L., Hussin H. Y., van Westen C. J., Glade T., Frigerio S., and Pasuto A.: Quantitative vulnerability assessment of buildings to debris-flows in Fella River Basin using runout modeling and damage data from the 29th of August 2003 event, in: Proceedings of the International Conference on Analysis and Management of Changing Risks for Natural Hazards, Padua, Italy, 18-19 November 2014.

Corominas, J., van Westen, C., Frattini, P., Cascini, L., Malet, J. P., Fotopoulou, S., Catani, F., Van Den Eeckhaut, M., Mavrouli, O., Agliardi, F., Pitilakis, K., Winter, M. G., Pastor, M., Ferlisi, S., Tofani, V., Hervás, J., and Smith, J. T.: Recommendations for the quantitative analysis of landslide risk, B. Eng. Geol. Environ., 73, 209-263, doi:10.1007/s10064-013-0538-8, 2014.

Crosta, G. B., Fratinni, P., Fugazza, F., Caluzzi, L., and Chen, J.: Cost-benefit analysis for debris avalance risk management, in:
Landslide Risk Management, edited by: Hungr, O., Fell, R., Couture, R., and Eberhardt, E., Talyor \& Francis, London, 533-541, 2005.

Dai, F. C., Lee C. F., and Ngai, Y. Y.: Landslide risk assessment and management: an overview, Eng. Geol., 64, 65-87, 2002.

EEA: Mapping the impacts of natural hazards and technological accidents in Europe: an overview of the last decade, European Environmental Agency Technical report 13, Office for Official Publications of the European Union, Luxembourg, 144 pp., 2010.

Einstein, H. H.: Special lecture: Landslide risk assessment procedure, in: Proceedings of the 5th International Symposium on Landslides, Lausanne, Switzerland, 10-15 July, 1075-1090, 1988.

EM-DAT: The OFDA/CRED international disaster database, Université Catholique de Louvain, Brussels, available at: www. emdat.be (last access: 28 May 2015), 2003.

Fell, R. and Hartford, D.: Landslide risk management, in: Landslide Risk Assessment, edited by: Cruden, D. and Fell, R., Balkema, Rotterdam, 51-109, 1997.

Fell, R., Ho, K. K. S., Lacasse, S., and Leroi, E.: A framework for landslide risk assessment and management, in: Landslide Risk Management, edited by: Hungr, O., Fell, R., Couture, R., and Eberhardt, E., Taylor \& Francis, London, 3-25, 2005.

Fell, R., Corominas, J., Bonnard, C., Cascini, L., Leroi, E., and Savage, W. Z.: Guidelines for landslide susceptibility, hazard and risk zoning for land use planning, Eng. Geol., 102, 85-98, 2008.

FEMA: Understanding your risks: Identifying hazards and estimated losses, Federal Emergency Management Agency, Washington DC, 168 pp., 2001.

Frigerio, S. and van Westen, C. J.: RiskCity and WebRiskCity: Data collection, display, and dissemination in a multi-risk training package, Cartography and geographic information science, 37, 119-135, 2010.

Frigerio, S., Kappes, M., Blahůt, J., and Skupinski, G.: The use of geo-information and modern visualization tools for risk communication, in: Mountain Risks: From Prediction to Management and Governance, Advances in Natural and Technological Hazards Research, edited by: van Asch, T., Corominas, J., Greiving, S., Malet, J. P., and Sterlacchini, S., 34, Springer, Dordrecht, the Netherlands, 383-407, 2014.

Fuchs, S., Heiss, K., and Hübl, J.: Towards an empirical vulnerability function for use in debris flow risk assessment, Nat. Hazards Earth Syst. Sci., 7, 495-506, doi:10.5194/nhess-7-4952007, 2007.

Furdu, I., Tomozei, C., and Pandele, I.: Improving management of risks and natural disasters by regional GIS distributed application, Environ. Eng. Manag. J., 12, 11-16, 2013.

Giuliani, G. and Peduzzi, P.: The PREVIEW Global Risk Data Platform: a geoportal to serve and share global data on risk to natural hazards, Nat. Hazards Earth Syst. Sci., 11, 53-66, doi:10.5194/nhess-11-53-2011, 2011.

Glade, T., Anderson, M., and Crozier, M. J. (Eds.): Landslide Hazard and Risk, John Wiley \& Sons Lt, Chichester, UK, 824 pp., 2005.

Guzzetti, F., Peruccacci, S., Rossi, M., and Stark, C. P.: Rainfall thresholds for the initiation of landslides in central and southern Europe, Meteorol. Atmos. Phys., 98, 239-267, 2007.

Haimes, Y. Y.: Risk Modelling, Assessment and Management, 3rd Edition, John Wiley \& Sons, Hoboken, 1009 pp., 2009. 
Hungr, O.: Some methods of landslide hazard intensity mapping, in: Landslide Risk Assessment, edited by: Cruden, D. M. and Fell, R., A.A. Balkema, Rotterdam, 215-226, 1997.

Hussin, H. Y., Ciurean, R., Frigerio, S., Marcato, G., Calligaris, C., Reichenbach, P., van Westen, C., and Glade, T.: Assessing the effect of mitigation measures on landslide hazard using 2D numerical runout modelling, in: Landslide Science for a Safer Geoenvironment, edited by: Sassa, K., Canuti, P., and Yin, Y., Springer International Publishing, Cham, 679-684, 2014a.

Hussin, H. Y., Chen, L., Ciurean, R. L., van Westen, C. J., Reichenbach, P., and Sterlacchini, S.: Analysing changes in landslide risk using multi temporal landslide susceptibility and run-out modeling on a regional scale, in: Proceedings of the International Conference on Analysis and Management of Changing Risks for Natural Hazards, Padua, Italy, 18-19 November 2014b.

IncREO: Deliverable report of the project, available at: http://www. increo-fp7.eu/ (last access: 28 May 2015), 2014.

ISSMGE TC32 (International Society for Soil Mechanics and Geotechnical Engineering - Technical Committee on Risk Assessment and Management): Glossary of Risk Assessment Terms - Version 1, available at: http://140.112.12.21/issmge/ 2004Glossary_Draft1.pdf (last access: 15 October 2015), 2004.

Jaboyedoff, M., Aye, Z. C., Derron, M. H., Nicolet, P., and Olyazadeh, R.: Using the consequence-frequency matrix to reduce the risk: examples and teaching, in: Proceedings of the International Conference on Analysis and Management of Changing Risks for Natural Hazards, Padua, Italy, 18-19 November 2014.

Kotz, S. and van Drop, J. R.: Beyond Beta: other continuous families of distributions with bounded support and applications, World Scientific, Singapore, 289 pp., 2004.

Krejčí, O., Baroň, I., Bíl, M., Hubatka, F., Jurová, Z., and Kirchner, K.: Slope movements in the Flysch Carpathians of Eastern Czech Republic triggered by extreme rainfalls in 1997: a case study, Physics and Chemistry of the Earth, Parts A/B/C, 27, 1567-1576, 2002.

Lan, H. X., Martin, C. D., Froese, C. R., Kim, T. H., Morgan, A. J., Chao, D., and Chowdhury, S.: A web-based GIS for managing and assessing landslide data for the town of Peace River, Canada, Nat. Hazards Earth Syst. Sci., 9, 1433-1443, doi:10.5194/nhess9-1433-2009, 2009.

Lee, E. M. and Jones, D. K. C.: Landslide Risk Assessment, Thomas Telford, Chicago, 524 pp., 2004.

Müller, M., Vorogushyn, S., Maier, P., Thieken, A. H., Petrow, T., Kron, A., Büchele, B., and Wächter, J.: CEDIM Risk Explorer a map server solution in the project "Risk Map Germany", Nat. Hazards Earth Syst. Sci., 6, 711-720, doi:10.5194/nhess-6-7112006, 2006.

OpenQuake platform: available at :https://platform.openquake.org/, last access: 4 March 2015.

Papathoma-Köhle, M., Keiler, M., Totschnig, R., and Glade, T.: Improvement of vulnerability curves using data from extreme events: debris flow event in South Tyrol, Nat. Hazards, 64, 20832105, 2012.

Peggion, M., Bernardini, A., and Masera, M.: Geographic Information Systems and Risk Assessment, Scientific and Technical Research series EUR, Office for Official Publications of the European Communities, Luxembourg, 50 pp., 2008.
Pessina, V. and Meroni, F.: A WebGIS tool for seismic hazard scenarios and risk analysis, Soil Dyn. Earthq. Eng., 29, 1274-1281, 2009.

Pine, J. C.: Natural Hazards Analysis: Reducing the Impact of Disasters, CRC Press, Boca Raton, FL, 304 pp., 2008.

Quan Luna, B., Blahut, J., van Westen, C. J., Sterlacchini, S., van Asch, T. W. J., and Akbas, S. O.: The application of numerical debris flow modelling for the generation of physical vulnerability curves, Nat. Hazards Earth Syst. Sci., 11, 2047-2060, doi:10.5194/nhess-11-2047-2011, 2011.

Raaijmakers, R., Krywkow, J., and van der Veen, A.: Flood risk perceptions and spatial multi-criteria analysis: an exploratory research for hazard mitigation, Nat Hazards., 46, 307-322, 2008.

Salvati, P., Balducci, V., Bianchi, C., Guzzetti, F., and Tonelli, G.: A WebGIS for the dissemination of information on historical landslides and floods in Umbria, Italy, Geoinformatica, 13, 305-322, 2009.

Sangati, M.: Flash flood analysis and modelling in mountain regions, Ph.D. thesis, University of Padova, Italy, available at: http://paduaresearch.cab.unipd.it/1686/1/tesi_dottorato_ Marco_Sangati_090129.pdf (last access: 28 May 2015), 2009.

Sassa, K. and Wang, G. H.: Mechanism of landslide-triggered debris flows: Liquefaction phenomena due to the undrained loading of torrent deposits, in:Debris flow hazards and related phenomena, edited by: Jakob, K. and Hungr, O., Praxis, Springer Berlin Heidelberg, 81-104, 2005.

Schelhorn, S. J., Herfort, B., Leiner, R., Zipf, A., and de Albuquerque, J. P.: Identifying elements at risk from OpenStreetMap: the case of flooding, in: Proceedings of the 11th International Conference ISCRAM, edited by: Hiltz, S. R., Pfaff, M. S., Plotnick, L., and Shih, P. C., University Park, Pennsylvania, USA, 508-512, 2014.

Scolobig, A., Broto, V. C., and Zabala, A.: Integrating multiple perspectives in social multicriteria evaluation of flood-mitigation alternatives: the case of Malborghetto-Valbruna, Environ. Plann. C, 26, 1143-1161, 2008.

Sterlacchini, S., Akbas, S. O., Blahut, J., Mavrouli, O. C., Garcia, C., Luna, B. Q., and Corominas, J.: Methods for the characterization of the vulnerability of elements-at-risk, in: Mountain Risks: From Prediction to Management and Governance, Advances in Natural and Technological Hazards Research, edited by: van Asch, T., Corominas, J., Greiving, S., Malet, J. P., and Sterlacchini, S., 34, Springer, Dordrecht, the Netherlands, 233273, 2014.

Sugumaran, R., Meyer, J., and Davis, J.: A web-based environmental decision support system (WEDSS) for environmental planning and watershed management, J. Geogr. Syst., 6, 1-16, 2004.

Uzielli, M., Nadim, F., Lacasse, S., and Kaynia, A. M.: A conceptual framework for quantitative estimation of physical vulnerability to landslides, Eng. Geol., 102, 251-256, 2008.

van Westen, C.J., van Asch, T. W. J., and Soeters, R.: Landslides hazard and risk zonation - why is it still so difficult?, Bull. Eng. Geol. Env., 65, 167-184, 2006.

van Westen, C. J., Quan Luna, B., Vargas Franco, R. D., Malet, J. P., Jaboyedoff, M., Horton, P., and Kappes, M.: Development of training materials on the use of geo-information for multi-hazard risk assessment in a mountainous environment, in: Proceedings of the International Conference on Mountain Risks: bringing science to society, Firenze, Italy, 24-26 November, 469-475, 2010. 
van Westen, C. J., Kappes, M. S., Luna, B. Q., Frigerio, S., Glade, T., and Malet, J. P.: Medium-scale multi-hazard risk assessment of gravitational processes, in: Mountain Risks: From Prediction to Management and Governance, Advances in Natural and Technological Hazards Research, edited by: van Asch, T., Corominas, J., Greiving, S., Malet, J. P., and Sterlacchini, S., 34, Springer, Dordrecht, the Netherlands, 201-231, 2014.

Westrope, C., Banick, R., and Levine, M.: Groundtruthing OpenStreetMap building damage assessment, Procedia Eng., 78, 2939, 2014.
Yang, C. P., Wong, D. W., Yang, R., Kafatos, M., and Li, Q.: Performance-improving techniques in web-based GIS, Int. J. Geogr. Inf. Sci., 19, 319-342, 2005.

Zêzere, J. L., Trigo, R. M., and Trigo, I. F.: Shallow and deep landslides induced by rainfall in the Lisbon region (Portugal): assessment of relationships with the North Atlantic Oscillation, Nat. Hazards Earth Syst. Sci., 5, 331-344, doi:10.5194/nhess-5-3312005, 2005. 